\title{
Evaluation of expression analysis of putrescine n-methyltransferase gene during different stages of growth in the medicinal plant Physalis divaricata (Solanaceae)
}

\author{
ELHAM MOALLEM ${ }^{1}$, ABDOLLAH GHASEMIPIRBALOUTI ${ }^{2}$, TAHER NEJADSATTARI ${ }^{1}$, \\ ALIREZA IRANBAKHSH ${ }^{1}$, IRAJ MEHREGAN ${ }^{1, \bullet}$ \\ ${ }^{1}$ Department of Biology, Science and Research Branch, Islamic Azad University, Tehran, Iran, Tel: +98-2144865327, `email: iraj@daad-alumni.de, \\ imehregan@srbiau.ac.ir \\ ${ }^{2}$ Department of Medicinal Plants, Shahrekord Branch, Islamic Azad University, Shahrekord, Iran
}

Manuscript received: 2 March 2017. Revision accepted: 8 September 2017.

\begin{abstract}
Moallem E, Ghasemipirbalouti A, Nejadsattari T, Iranbakhsh A, Mehregan I. 2017. Evaluation of expression analysis of putrescine n-methyltransferase gene during different stages of growth in the medicinal plant Physalis divaricata (Solanaceae). Biodiversitas 18: 1430-1437. Physalis divaricata (Solanaceae) is one of the most prevalent weeds in summer crops. Putrescine Nmethyltransferase (PMT) is a key enzyme in the biosynthesis of nicotine, tropane alkaloids atropine, scopolamine, cocaine, and calystegines. The present study set to compare PMT gene expression during different growth stages of Ph. divaricata using RT-qPCR assay. RNA extraction was performed from root and leaf samples of a total number of 40 individuals Ph. divaricata at different growth stages (late vegetative and fruiting stages) collected from southwestern Iran. RT-qPCR of cDNA reversely synthesized from RNA was carried out using SYBR ${ }^{\circledR}$ Premix Ex Taq ${ }^{\mathrm{TM}}$ II kit. PMT gene expression levels were analyzed using $\Delta \Delta \mathrm{CT}$ method. The results showed that expression level of $P M T$ in late vegetative stage samples was significantly higher compared to fruiting stage samples. The expression level of PMT similarly changed in root and leaf samples. Direct visualization of alkaloids in different tissues using Wagner histochemical tests showed more concentrations of alkaloids in leaf idioblasts and root stele.
\end{abstract}

Keyword: Histochemical, Physalis divaricata, PMT, RT-qPCR, Wagner test

\section{INTRODUCTION}

Of the estimated about 500,000 plant species, only a small group has been investigated phytochemically, and even a smaller group has been studied in terms of their pharmacological properties (Hamburger and Hostettmann 1991).

Physalis divaricata D. Don (Solanaceae) is an annual ground cherry, has recently become a most serious damaging weed in many minor crops and summer annual crops. The generic name Physalis is originated from the Greek name phusa; the fruit is attached and in bladder shape of flower bowl with five clefts, which increases in size after falling off the corolla. It bears smooth, dark-green ovate, lanceolate- or rhomboid-ovate, acuminate leaves, and 4-5 mm long yellowish-white flowers. Fruits are yellow, spherical and ca. $10 \mathrm{~mm}$ in diameter, containing numerous reniform-lenticular, reticulate-rugose seeds. $P h$. divaricata is distributed in India, Pakistan, and Afghanistan, and recently introduced in Iran (SchönbeckTemesy 1972; Rates 2001).

Physalis divaricata is an invasive weed with a length of $15-60 \mathrm{~cm}$. Its yellow color flowers are cup-shaped and solitary, which appear from May to July. The number of seeds produced can range from 126 to 16,300 per plant; also, it produces 4 to 70 seeds per berry. This weed prefers rich nutrient soils. According to the preliminary observations, the freshly harvested seeds indicate high levels of dormancy. This species has become destructive to annual summer crops, such as potato, tomato, maize, sugar beet, and some minor crops in Iran. The sticky materials released from $\mathrm{Ph}$. divaricata berries cause harvest problems and crop quality reduction. One of the most important stages in the life cycle of $P h$. divaricata is seed germination. Physalis divaricata seeds apparently have no special tools to disperse for long and short distances (Stanton and Lemerle 2012). Different factors can highly affect seed germination and seedling emergence. These include light (Huebner 2011), osmotic potential (Boyd and Van Acker 2004), seed burial depth (Wilson et al. 2006), and temperature (Foley 2008). Interactions of those factors with internal conditions of seeds would also have impact on seed germination. Chemical control of $P h$. divaricata is difficult due to its proximity to other Solanaceae crops, especially when it grows in the fields of such crops (Gorski and Wertz 1987). Development of effective control measures, prediction of invasion potential, and weed management would be easier with understanding of the factors affecting seed germination and seedling emergence (Ghersa and Holt 1995).

Due to its alkaloids. Ph. divaricata, an invasive weed to many summer fodder fields, is toxic to domestic animals. It is important to investigate the amount of alkaloid production during different developmental stages. Putrescine N-methyltransferase (PMT) is one of the most important enzymes of plant secondary metabolism at the 
beginning of the specific nicotine biosynthesis, calystegines, and tropane alkaloids that are glycosidase inhibitors with nortropane structure. PMT is fictitious to have developed from spermidine synthases (SPDS), participating in ubiquitous polyamine metabolism (Teuber et al. 2007). PMT in the nicotine biosynthesis is the first pathway-specific enzyme of tropane alkaloids atropine, cocaine, scopolamine, and calystegines. Calystegines are polyhydroxy alkaloids with strong glycosidase inhibitory activity. They occur fictitiously more among the plant kingdom before the distribution of tropane alkaloids (Griffin and Lin 2000); Brassicaceae and Moraceae contain calystegines (Brock et al. 2006). The first PMT cDNA sequence was obtained by subtractive hybridization on cDNA banks exploiting different transcript levels between tobacco cultivars rich and poor in nicotine (Hibi et al. 1994). Furthermore, PMT cDNA sequences from Nicotiana species were found screening genomic DNA libraries by 5c-terminal PMT-fragments as probes that contain 33 base pairs repeated two to nine times (Hashimoto et al. 1998).

Northern blot analysis is usually used for determination of gene expression levels. Large quantities of RNA are required for northern blot technique (Dean et al. 2002). RTqPCR is widely used for clinical diagnostic, the gene expression analyses, and for plant studies (Gachon et al. 2004). Many reference genes required for the normalization of expression signals are well characterized (Sturzenbaum and Kille 2001). Actin, glyceraldehyde-3-phosphate dehydrogenase, ribosomal genes, cyclophilin, 18s rRNA, and elongation factor 1-a (efla) are amongst those wellknown genes (Volkov et al. 2003). This list might also include adenine phosphoribosyltransferase (APRT) and tubulin. The vast majority of the studies dealing with housekeeping gene expression has mainly focused on human tissues, bacteria, and viruses. This figure is much fewer in case of plants, and usually limited to concerned plants such as barley, rice, poplar, Arabidopsis thaliana, and tobacco (Langer et al. 2002). Consequently, it is very important to choose an appropriate internal control for gene expression quantification (Nicot et al. 2005). Using 18s rRNA could be a valuable alternative for quantification of genes of interest (Kadam 1999).

Some studies have shown that PMT gene expression in Solanaceae is restricted to root. It is also shown that at least two members of PMT gene family are also involved in the regulation synthesis of alkaloid (Laue et al. 2000).

The PMT protein expression in nicotine was reported to be confined to roots and tropane alkaloid producing plants; the only exceptions were young potato tuber sprouts that synthesize calystegines and wounded tobacco leaves (Sachan and Falcone 2002). PMT transcript localization in roots was confirmed for all plants in this study and considered as typical for non-wounded plants. Calystegines transport or preceding metabolites in aerial organs must be inferred from the PMT expression usually restricted to roots (Korolev 2002). Other key alkaloids like physalins are usually diagnosed at the development and all stages of growth. Physalin concentration increases double during the developmental changes such as during flowering, twice the germination stage (El-Tayeb et al. 1997).
The present study aimed to evaluate expression analysis of PMT gene during different stages of growth (late vegetative and fruiting stages) in the medicinal plant $P h$. divaricata, using RT-qPCR assay.

Histochemistry is dealing with the identification of chemical components of cells and tissues (Dhale 2011). Alkaloids are degradation of the protein, investigated using two methods, namely, Mayer's reagent and Wagner's reagent (Dhale 2011). The present study aimed to investigate storage alkaloid that occurs in the tissues and cells of root and leaf of physalis divaricata at late vegetative and fruiting stages.

\section{MATERIALS AND METHODS}

\section{Plant material}

To determine the PMT gene, 20 samples at the late vegetative stage (Figure 1.A) and 20 samples at fruiting stage (Figure 1.B) were randomly selected. Root and leaf samples were obtained from $P h$. divaricata plants carefully. All samples were stored in RNAlater immediately after resection until use. The protocols of samples preparation referred to the Studies Committee at the Islamic Azad University of Shahrekord, Iran with grant number 17621105 .

\section{RNA extraction and cDNA synthesis}

$\mathrm{RNX}^{\mathrm{TM}}$-Plus solution (SinaClon, Iran) was used for extraction of total RNA from root and leaf samples. DNA was destroyed by adding an extended $1 \mathrm{~h}$ treatment with DNase I. Quality of RNA was checked on a Thermo Scientific NanoDrop ${ }^{\mathrm{TM}} 1000$ spectrophotometer. Presence and integrity of RNA were initially checked on 2\% agarose gel. Synthesis of complementary DNA (cDNA) was performed by taking $1 \mu$ and using random hexamer priming and PrimeScript ${ }^{\mathrm{TM}}-\mathrm{RT}$ reagent kit (TaKaRa, Japan). The concentration of synthesized cDNA was checked spectrophotometrically.

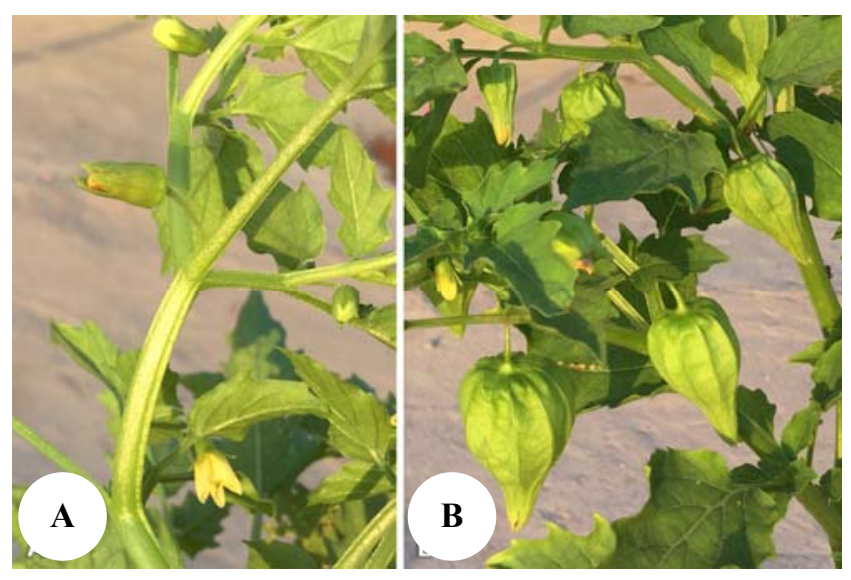

Figure 1. Physalisdivaricatalate vegetative stage (A), and at fruiting stage (B) 


\section{Quantitative Real-Time PCR}

Assessment of all samples was carried out on a rotor gene 6000 Corbett detection system. qPCR became possible using SYBR®Premix Ex Taq $^{\mathrm{TM}}$ II kit (TaKaRa, Japan) after manufacturer's instructions. PCR conditions included an initial activation at $95^{\circ} \mathrm{C}$ for 5 min followed by 40 cycles of denaturation at $95^{\circ} \mathrm{C}$ for $15 \mathrm{~s}$ and annealing/extension at $65^{\circ} \mathrm{C}$ for $1 \mathrm{~min}$. Each run also included a "no template control" (NTC) consisting of H2O. Amplification of the target genes was performed by using following forward and reverse primer pairs: PMT-f: 5'TTC TGT CAA CTA CGC TTG GA-3'; PMT-r: 5'-CTA ATT CGG ACT TGA TAT GAG C-3'; 18S-f: 5'-GGG CAT TCG TAT TTC ATA GTC AGA G-3'; 18S-r: 5'CGG TTC TTG ATT AAT GAA AAC ATC CT-3'. Specificity of PCR products verification was performed using melting curve analysis. In order to verify product sizes and specificity, PCR products were checked on $2 \%$ agarose gel. All samples were normalized to $18 \mathrm{~s}$ rRNA. We used the mean value in each triplicate to calculate relative $P M T$ concentrations $(\triangle \mathrm{Ct}=\mathrm{Ct}$ mean $\mathrm{PMT}-\mathrm{Ct}$ mean $18 \mathrm{~s}$ rRNA). $2^{-\Delta \Delta \mathrm{Ct}}$ methods were used to calculate the expression fold changes. The qPCR assays were carried out with three replicates for each sample, and the data were presented as the mean \pm standard error of the mean (SEM).

\section{Histochemical tests}

In order to find the cells and tissues where alkaloids being stored, we tried to investigate the fresh tissues using the method first described by Furr and Mahlberg (1981). This method is specially designed to show the actual places of alkaloid storage. The histochemical tests were performed with fresh tissue samples, sectioned by hand from median region of the leaves, and roots cross-sections were taken from different regions. Looking for alkaloid components, we screened all plant parts at different growth stages. They are not recognizable morphologically.Sections which store alkaloid compounds are determined using the Wagner reagent. Wagner reagents and Dittmar reagent were introduced by Furr and Mahlberg (1981). The sections were installed in $50 \%$ glycerin on a slide with coverslip according to the semi-permanent slide preparation methodology described previously (Johansen 1940). An optical microscope (Olympus AX70) coupled with a digital camera was used to obtain photomicrographs.

\section{Statistical analysis}

In order to determine the significance, a pairwise fixed reallocation randomization test with 2000 iterations was performed using the REST 2009 software package. The software package SPSS v.20 (SPSS Inc., Chicago, IL) was used for statistical analysis of demographic and clinical data. Testing the relationship between categorical variables was made possible using Chi-square and independent ttests $(\mathrm{P}<0.05)$.

\section{RESULTS AND DISCUSSION}

\section{Results}

To explore the role of PMT in Ph. divaricata plants, the relative expression of mentioned gene was examined in late vegetative stage samples and the fruiting stage samples with RT-qPCR technique. The relative expression of PMT is shown in Figure 2. The relative expression level of PMT in samples at late vegetative stage was significantly higher(2 times) compared to the samples at the fruiting stage. On the other hand, the expression level of PMT had a similar change in both root and leaf samples ( 2 times).

The analysis by REST 2009 confirms the results. Overexpression of PMT in samples at a late vegetative stage in root samples is shown in Figure 3. As seen in Figure $3,50 \%$ of the relative expression has an expression distribution between $8 \%$ and $15 \%$.

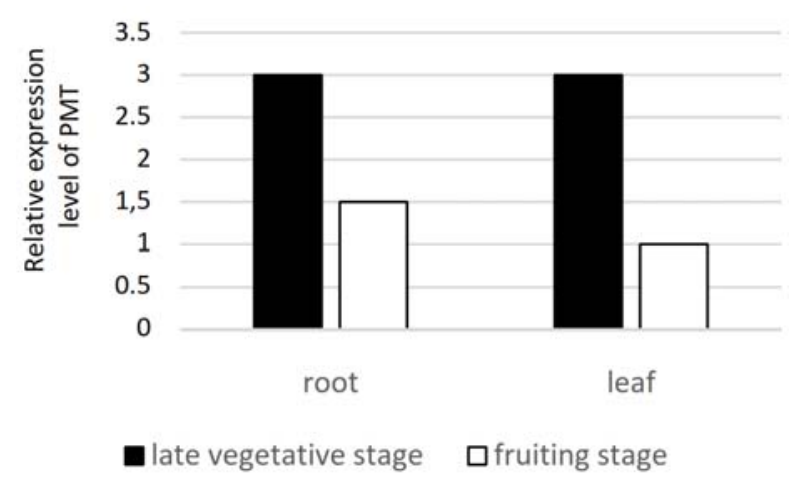

Figure 2. The relative expression level of PMT gene in two groups of samples

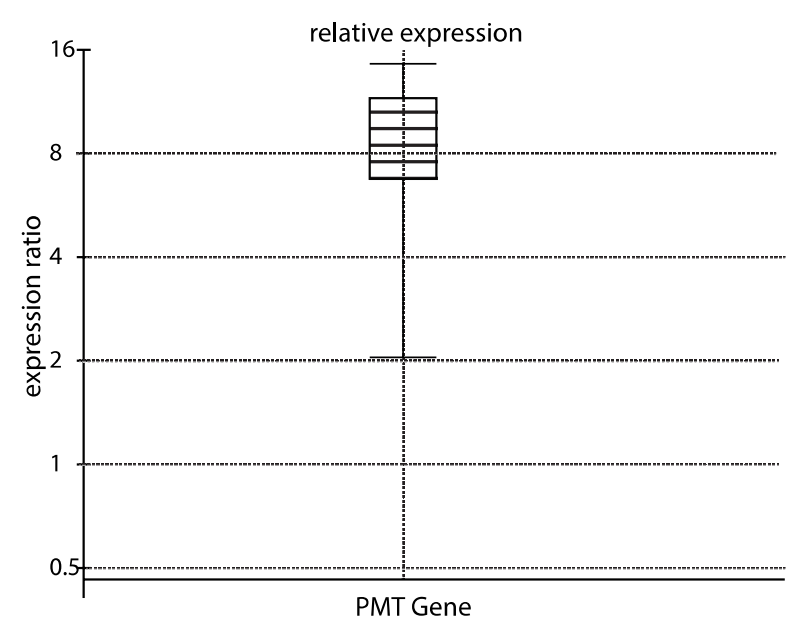

Figure 3. The relative expression level of PMT in root samples by REST 2009 


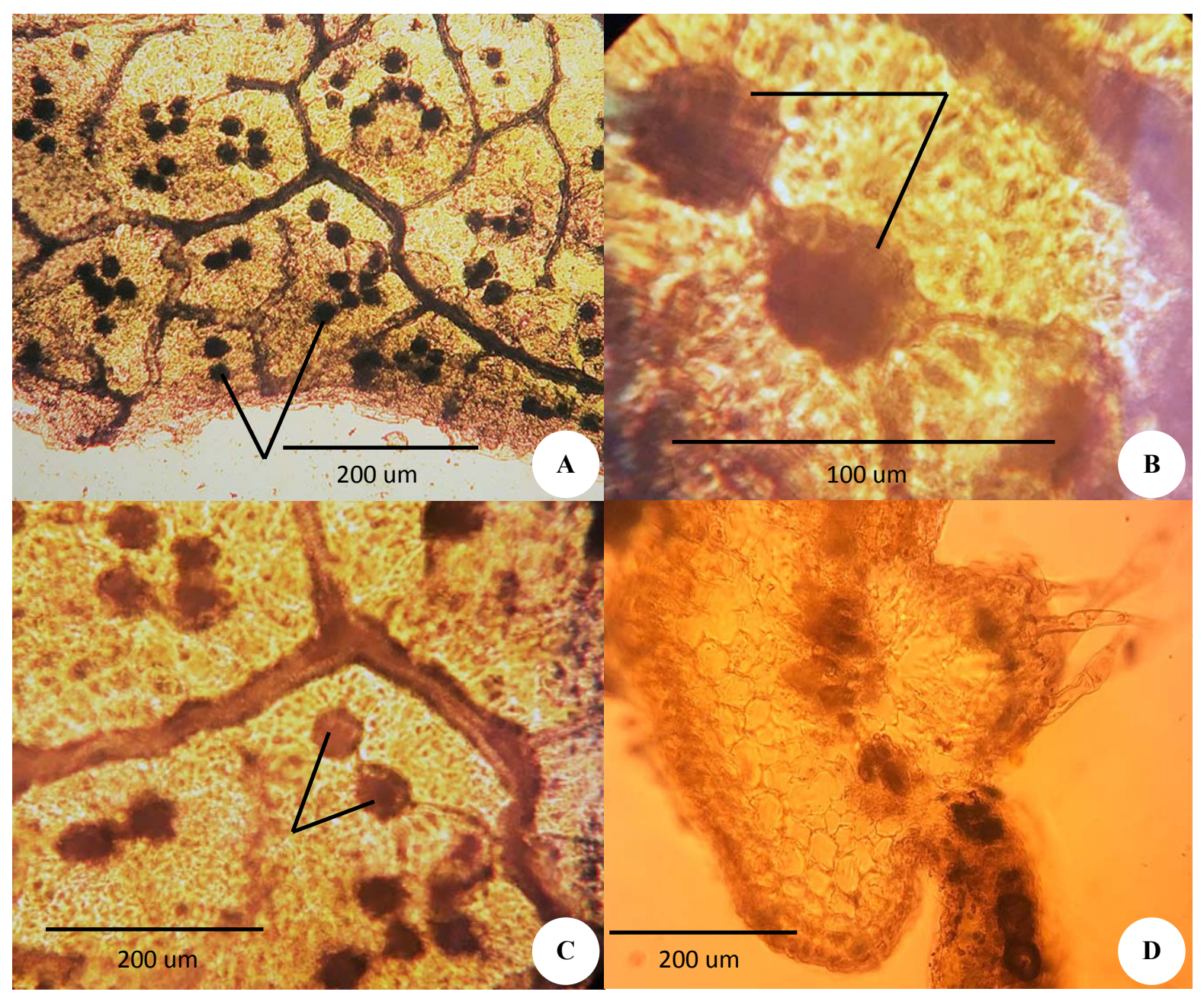

Figure 4. Sample spots treated with Wagner reagent; Physalis divaricata leaves at late vegetative stage detail are shown by cross arrows, under light microscopy. A. Leaf blade section stained with Wagner reagent. B. Detail of the mesophyll and several idioblasts in the parenchyma. C. Detail of the same parenchyma cells with a few idioblasts. D. Detail of the main vein.

In Mayer's reagent, alkaloids were observed in the scattered cells of mesophyll of leaves. In Wagner's reagent, alkaloids were found in the cells of mesophyll and cells of cortex parenchyma and pith parenchyma of the stem of Adhatoda zeylanica, Ruta graveiolence Vitex negundo (Dhale 2011).

Spots of Wagner reagents are seen in separate mesophilic cells or idioblasts cells of leaves at the end of the vegetative stage. (Figure 4.A, B, C), and at the fruiting stage, the spots have a density of less than the late vegetative stage (Figure 5.D), but more trimmed (Figure 5.A, B, C). Of course, they are not found in the parenchyma around the main vein (Figure 4.D). Wagner reaction reveals in the secondary phloem, primary phloem, epiderm, the pericycle bounded, under the epiderm, and medullary rays of root at late vegetative (Figure 4.A, B, C, $D, E, F)$ and fruiting stages that spots are only the pith and rey parenchyma cells with less density than the late vegetative stage (Figure 5A, B) of Ph. divaricata.
Alkaloids generally accumulate in specific cell types owing to their cytotoxicity and probable role in plant defense responses. For example, alkaloids are sequestered to isolated idioblasts and laticifers in Catharanthus roseus (St-Pierre et al. 1999), root endodermis, and stem cortex/pith in Thalictrum flavum (Samanani et al. 2005), and laticifers in opium poppy (Bird et al. 2003). Thus, in this research, alkaloids were evidenced in leaf idioblasts cells, root cortex/endodermis/stele by Wagner histochemical tests.

\section{Discussion}

Our results showed that Wagner reagent is a suitable tool to spot accumulation of alkaloids in different tissues and organs. Both aerial and underground parts of $P h$. divaricata showed to accumulate alkaloids. Accumulation of alkaloids in vegetative parts of Ph. divaricata increases with growth of those organs. The maximum amount of alkaloid accumulation was observed in the late vegetative 




Figure 5. Sample spots treated with Wagner reagent; the section in Physalis divaricata leaves at fruiting stage detail is shown by cross arrows, under light microscopy. A. Leaf blade section stained with Wagner reagent, B. Detail of the mesophyll and several idioblasts in the parenchyma, C, D. Detail of other parts of the mesophyll and several idioblasts in the parenchyma

stage. Accumulation of alkaloids in the vegetative parts start to decline with plant enters to the reproductive phase demonstrated by flowering and then fruiting. These results were firmly supported by investigation of PMT expression. Expression ratio of $P M T$ in the vegetative parts showed a peak at end of vegetative stage.

Alkaloids generally collect in specific cell types owing to their cytotoxicity and probable role in plant defense responses. They biosynthetic pathways are associated with different cell types (Ziegler and Facchini 2008). Tropane alkaloids are one of the main classes of plant-derived anticholinergic compounds, such as scopolamine and hyoscyamine, which occur in several Hyoscyamus, Datura, and Atropa species. Calystegines that function as selective glucosidase inhibitors are more widely spread than scopolamine and hyoscyamine in the plant kingdom and occur mainly in Solanaceae (Drager 2004).

Five PMT-encoding genes have been known in $N$. tabacum species: NtPMT1, NtPMT2, NtPMT3, NtPMT4, and NtPMT1a. In many studies, the rapid induction of $P M T$ encoding genes has been documented by wounding, herbivore attack, or exogenous applications of JA or MeJA in roots (Hara et al. 2000). H6H and PMT, catalyzing the last and first steps, respectively, in the tropane alkaloid scopolamine biosynthesis, localize to the pericycle in the roots of A. belladonna and Hyoscyamus muticus (Suzuki et al. 1999). This gene also catalyzes the first step in biosynthesis of nicotine and localizes to the outer cortex, endodermis, and xylem in Nicotiana sylvestris (Shoji et al. 2002). 


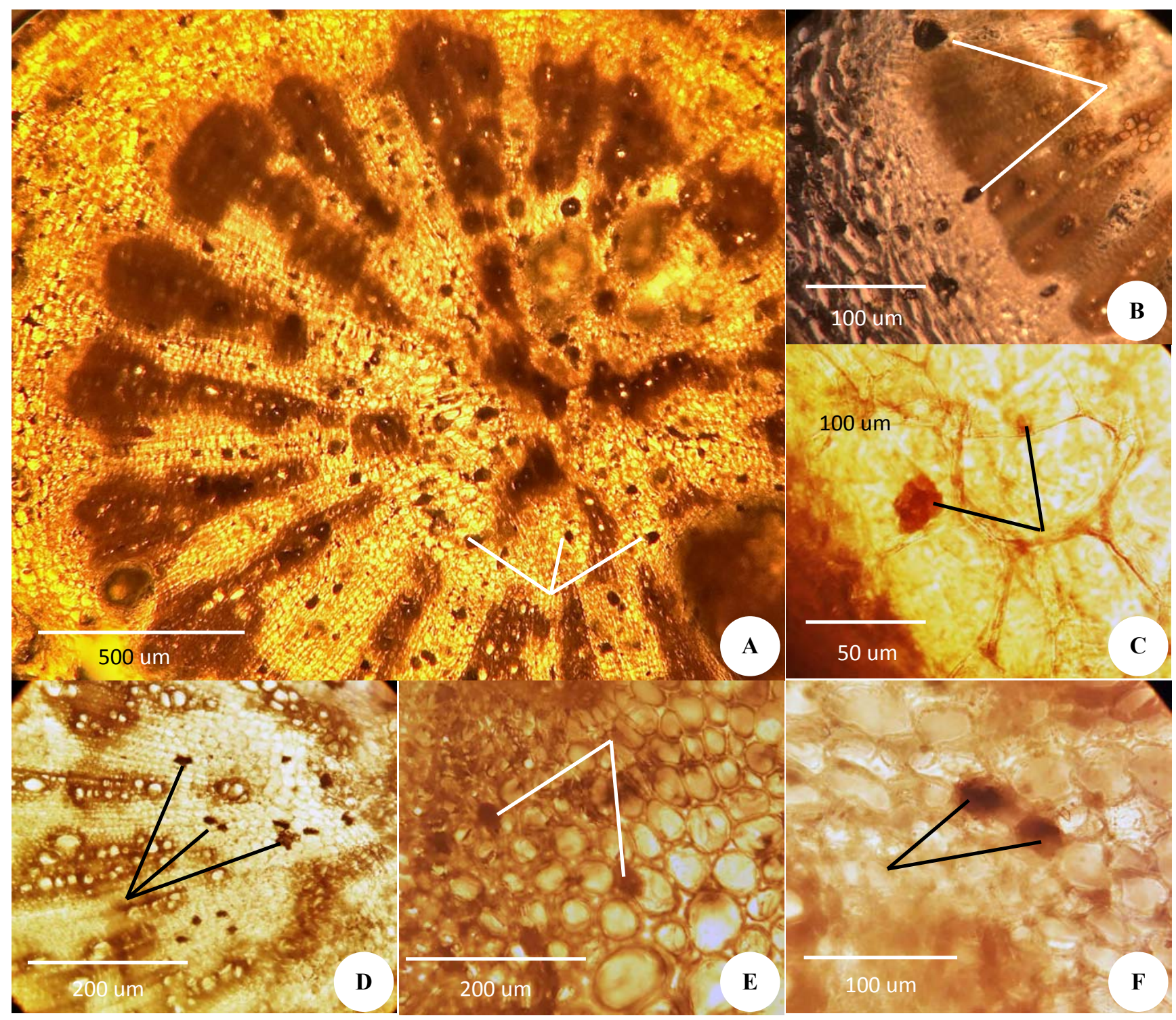

Figure 6. Sample spots treated with Wagner reagent; the section in Physalis divaricata roots at the late vegetative stage is shown by cross arrows, under light microscopy. A. Root section stained with Wagner reagent, B. Detail of the cortical parenchyma, C. Detail of the cortical parenchyma tissue and one parenchyma cell, D. Detail of the pith and rey parenchyma cells. E) Detail of the pith parenchyma tissue and several parenchyma cells. F) Detail of the pith parenchyma tissue and two parenchyma cells

In a similar study, Sachan and Falcone (2002) indicated that during the course of studying the regulation of alkaloid biosynthesis in Nicotiana, evidence was obtained for low PMT expression levels in leaves, which are abruptly upregulated over wounding. This upregulated expression was found to be highly localized and short-lived. On the other hand, expression was observed in leaves when they were wounded mechanically. Little evidence of longdistance signaling could be found as the expression was highly localized around the wound site. The results of Sachan and Falcone (2002) confirm the present findings. The relative $P M T$ expression level in samples at late vegetative stage had a significant increase compared to the samples at the fruiting stage. However, PMT expression level in both root and leaf samples had similar change.
Facchini et al. (1996) reported the effect of the alkaloids morphine concentration, confirmed in poppy cultivation. Their study showed that adding botrytis pathogenic stimuli to the poppy medium causes accumulation of sanguinarine (Facchini and Park 2003).

The spots created by Wagner reagent on roots' section at the fruiting stage are observed only in a few cells with less density than the late vegetative stage (Figure 7.A, B) and in the scattered mesophyll cells of leaves; at the fruiting stage, the density of spots is less (Figure 5.D) or the spots are seen less trimmed (Figures 5.A, B, C). Of course, the results are in line with the results of PMT gene expression. 


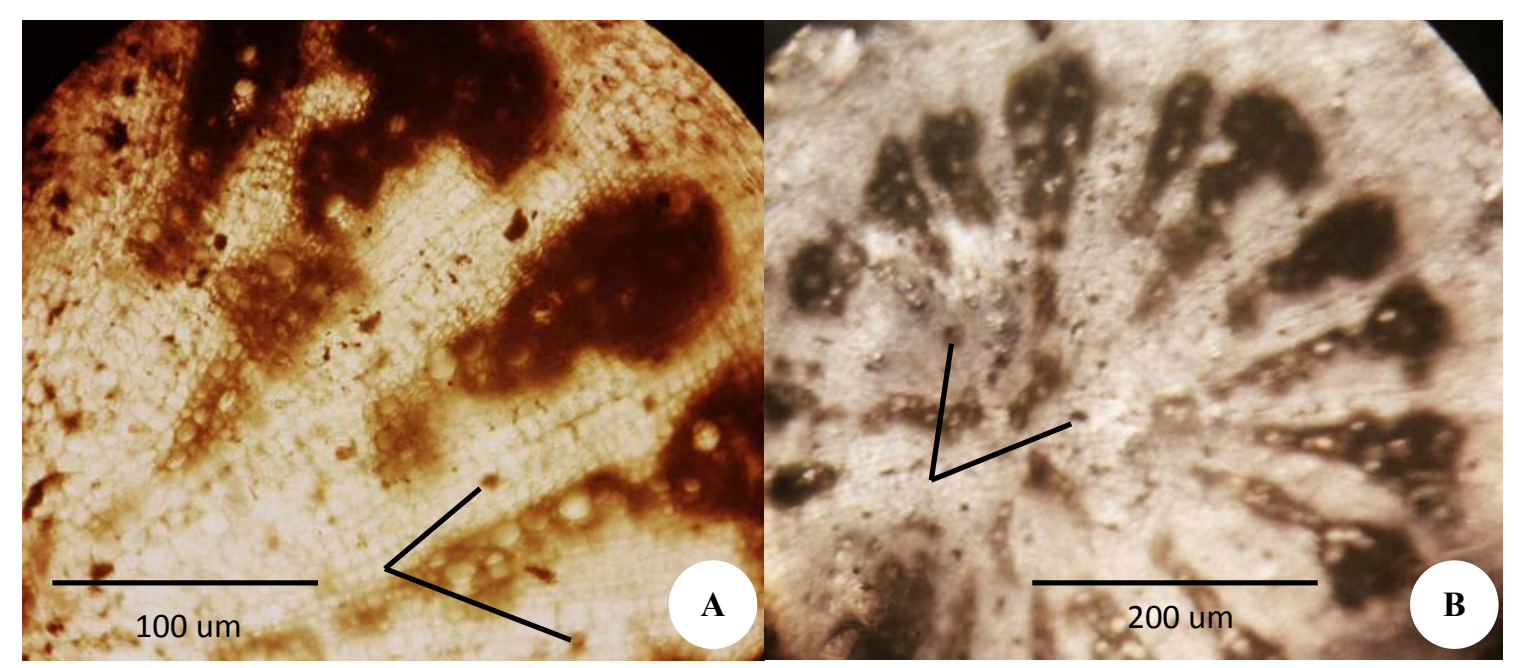

Figure 7. Sample spots treated with Wagner reagent; the section in Physalis divaricata roots at fruiting stage is shown by cross arrows, under light microscopy. A. Root section stained with Wagner reagent, B. Detail of the pith and rey parenchyma cells.

In conclusion and according to tropane alkaloid biosynthesis pathway and PMT gene expression, it seems that PMT gene in the root of $P h$. divaricata at late vegetative is extremely active. For further confirmation of tropane alkaloid biosynthesis pathway, it is required to determine the amounts of other tropinones in root and leaves at these two stages and compare these data.

\section{ACKNOWLEDGEMENTS}

The authors are grateful to the staff members of the Biotechnology Research Center of Islamic Azad University of Shahrekord Branch, Iran, for their sincere support. We also would like to thank Dr. Arida Susilowati for her valuable comments on an early version of the manuscript.

\section{REFERENCES}

Bird DA, Franceschi VR, Facchini PJ. 2003. A tale of three cell types: alkaloid biosynthesis is localized to sieve elements in opium poppy. Plant Cell15: 2626-2635.

Boyd N, Van Acker R. 2004. Seed germination of common weed species as affected by oxygen concentration, light, and osmotic potential. Weed Sci 52: 589-596.

Brock A, Herzfeld T, Paschke T, Koch M, Draeger B. 2006. Brassicaceae contain nortropane alkaloids. Phytochemistry 67: 2050-2057.

Dean JD, Goodwin PH, Hsiang T. 2002. Comparison of relative RT-PCR and northern blot analyses to measure expression of b-1,3-glucanase in Nicotiana benthamiana infected with Colletotrichum destructivum. Plant Mol Biol Rep20: 347-356.

Dhale DA. 2011. Histochemical investigation of some medicinal plant. Adv Res Pharmaceut Biol 1 (2): 147-154.

Drager B. 2004. Chemistry and biology of calystegines. Nat Prod Rep 21: 211-23.

El-Tayeb EA, Al-Ansari AS, Roddick JG. 1997. Changes in the steroidal alkaloid solasodine during development of Solanum nigrum and Solanum incanum. Phytochemistry 46: 489-494.
Facchini PJ, Johnson AG, Poupart J, De Luca V. 1996. Uncoupled defense gene expression and antimicrobial alkaloid accumulation in elicited opium poppy cell cultures. Plant Physiol 111: 687-697.

Facchini PJ, Park SU. 2003. Development and inducible accumulation of gene transcripts involved in alkaloid biosynthesis in opium poppy. Phytochemistry 64: 177-186.

Foley ME. 2008. Temperature and moisture status affect after ripening of leafy spurge (Euphorbia esula) Seeds. Weed Sci 56: 237-243.

Furr Y, Mahlberg PG. 1981. Histochemical analysis of laticifers and glandular trichomes in Cannabis sativa. Nat Prod 44: 153-159.

Gachon C, Mingam A, Charrier B. 2004. Real-time PCR: what relevance to plant studies. J Exp Bot 55: 1445-1454.

Ghersa CM, Holt JS. 1995. Using phenology prediction in weed management. Weed Res 35: 461-470.

Gorski SF, Wertz MK. 1987. Tomato (Lycopersicon esculentum) and eastern black nightshade (Solanum ptycanthum) tolerance to aciflurofen. Weed Technol 1: 278-281.

Griffin WJ, Lin GD. 2000. Chemotaxonomy and geographical distribution of tropane alkaloids. Phytochemistry 53: 623-637.

Hamburger M, Hostettmann K. 1991. Phytochemistry bioactive in plants. The link between phytochemistry \& medicine. Phytochemistry 30 : 3864-3867.

Hara K, Yagi M, Koizumi N, Kusano T, Sano H. 2000. Screening of wound-responsive genes identifies an immediate-early expressed gene encoding a highly charged protein mechanically wounded tobacco plants. Plant Cell Physiol 41: 684-691.

Hashimoto T, Tamaki K, Suzuki K, Yamada Y. 1998. Molecular cloning of plant spermidine synthases. Plant Cell Physiol 39: 73-79.

Hibi N, Higashiguchi S, Hashimoto T, Yamada Y. 1994. Gene expression in tobacco low-nicotine mutants. Plant Cell 6: 723-735.

Huebner CD. 2011. Seed mass, viability, and germination of japanese stiltgrass (Microstegium vimineum) under variable light and moisture conditions. Invasive Plant Sci Manag 4: 274-283.

Johansen DA. 1940. Plant Microtechnique. McGraw-Hill Book Co Inc, New York.

Kadam VB. 1999. Histochemical investigations of different organs of three Endangered medicinal taxa of South Gujarat Forests. Phytol Res 12 (1-2): 109-112.

Korolev S, Ikeguchi Y, Skarina T, Beasley S, Arrowsmith C, Edwards A, Joachimiak A, Pegg AE, Savchenko A. 2002. The crystal structure of spermidine synthase with a multisubstrate adduct inhibitor. Nat Struct Biol 9: 27-31.

Langer K, Ache P, Geiger D, Stinzing A, Arend M, Wind C, Regan S, Fromm J, Hedrich, R. 2002. Poplar potassium transporters capable of controlling $\mathrm{K}+$ homeostasis and $\mathrm{K}+$ dependent xylogenesis. Plant $\mathrm{J}$ 32: $997-1009$ 
Laue G, Preston CA, Baldwin IT. 2000. Fast track to the trichome: induction of $\mathrm{N}$-acyl nornicotines precedes nicotine induction in Nicotiana repanda. Planta 210: 510-514.

Nicot N, Hausman JF, Hoffmann L, Evers D. 2005. Housekeeping gene selection for real-time RT-PCR normalization in potato during biotic and abiotic stress. J Exp Bot 56 (421): 2907-2914.

Rates, SMK. 2001. Plants as a source of drugs, Toxicon 39: 603-613.

Sachan N, Falcone DL. 2002. Wound-induced gene expression of putrescine $\mathrm{N}$-methyltransferase in leaves of Nicotiana tabacum. Phytochemistry 61: 797-805.

Samanani N, Park SU, Facchini PJ. 2005. Cell type-specific localization of transcripts encoding nine consecutive enzymes involved in protoberberine alkaloid biosynthesis. Plant Cell 17: 915-926

Schönbeck-Temesy A. 1972. Solanaceae. In: Rechinger KH (ed.) Flora Iranica 100. Akademische Druck- u. Verlagsanstalt. Graz, Austria.

Shoji T, Winz R, Iwase T, Nakajima K, Yamada Y, Hashimoto T. 2002. Expression patterns of two tobacco isoflavone reductase-like genes and their possible roles in secondary metabolism in tobacco. Plant Mol Biol 50: 427-440.

Stanton RWU, Lemerle D. 2012. Factors affecting silverleaf nightshade (Solanum elaeagnifolium) germination. Weed Sci 60: 42-47.

St-Pierre B, Vazquez-Flota FA, De Luca V. 1999. Multicellular compartmentation of Catharanthus roseus alkaloid biosynthesis predicts intercellular translocation of a pathway intermediate. Plant Cell 11: 887-900

Sturzenbaum SR, Kille P. 2001. Control genes in quantitative molecular biological techniques: the variability of invariance. Comp Biochem Physiol B130: 281-289.

Suzuki K, Yun DJ, Chen XY, Yamada Y, Hashimoto T. 1999. An Atropa belladonna hyoscyamine $6 \beta$-hydroxylase gene is differentially expressed in the root pericycle and anthers. Plant Mol Biol 40: 141152.

Teuber M, Azemi ME, Namjoyan F, Meier AC, Wodak A, Brandt W, Dräger B. 2007. Putrescine N-methyltransferases--a structurefunction analysis. Plant Mol Biol 63: 787-801.

Volkov RA, Panchuk II, Schöffl F. 2003. Heat-stress-dependency and developmental modulation of gene expression: the potential of housekeeping genes as internal standards in mRNA expression profiling using real-time RT-PCR. Exp Bot 54: 2343-2349.

Wilson DG, Burton MG, Spears JF, York AC. 2006. Doveweed (Murdannia nudiflora) germination and emergence as affected by temperature and seed burial depth. Weed Sci 54: 1000-1003.

Ziegler J, Facchini PJ. 2008. Alkaloid biosynthesis: metabolism and trafficking. Ann Rev Plant Biol 59: 735-769. 